\title{
The Transient Stability Study of a Synchronous Generator Based on the Rotor Angle Stability
}

\author{
Fetissi Selwa, Labed Djamel, Labed Imen \\ Laboratory of Electrical Engineering of Constantine, Department of Electrical Engineering, \\ Frère Mentouri Constantine 1 University, Constantine, Algeria
}

\section{Article Info \\ Article history: \\ Received May 2, 2015 \\ Revised Jul 20, 2015 \\ Accepted Aug 5, 2015 \\ Keyword: \\ Critical clearing time \\ Rotor angle stability \\ Synchronous generator \\ Transient stability}

\begin{abstract}
Transient stability is an important aspect in the operation of electrical power system. In case of fault occurs in the system, the determining of fault clearing time of circuit breaker is considered one of the main factors to ensure power transfer of the system. This paper is aim to study the transient stability of single machine infinite bus system (SMIB), based on the rotor angle stability. The study is performed to determine the influence of the critical clearing time of the circuit breakers on the rotor angle stability of the generator in the case of three phase fault. For obtaining and determining numerically the nature of the rotor angle of machine, we applied the Step-by-step method for different values of fault clearing time. The results of simulation indicate that determine of critical clearing time is a major evaluation in stability studies. The system model is created in MATLAB/ SIMULINK software.
\end{abstract}

Copyright (c) 2015 Institute of Advanced Engineering and Science. All rights reserved.

\section{Corresponding Author:}

Fetissi Selwa,

Laboratory of Electrical Engineering of Constantine,

Department of Electrical Engineering,

Frère Mentouri Constantine 1University,

Road d'Ain El Bey, Constantine 25000, Algeria.

Email: Selwa.f@hotmail.com

\section{INTRODUCTION}

Studies of the transient stability have been recognized as an essential part in the planning of electrical systems, in order to ensure the system operation in good condition and return to normal or stable state after having been subjected to some form of disturbance. Power system stability is the ability of the system to remain in operating equilibrium or synchronism, while disturbance occur on the system [1]-[4].

Transient stability is the ability of the power system to maintain synchronism when it is subjected to a severe transient perturbation [2], [5]-[7], like the case of separation of lines or electrical generators.

The transient stability depends not only on the amplitude of the disturbance and the starting point of operation but also it depends on the dynamic characteristics of the system [7]. It manifests in the short term as a widening gap a periodically certain angles of the rotor [8]. In this paper, we are interested in the stability study of the rotor angle.

Rotor angle stability is the synchronous machines capacity of an interconnected power system to remain in synchronism after a disturbance. The rotor angle of the generator depends on the balance between the electromagnetic torque and mechanical torque. In other words, the system is unstable if the angle difference between two interconnected generators increases indefinitely or transient oscillation caused by a disturbance, is not sufficiently damped in the evaluation time [9].

Rotor angle stability is further classified into small disturbance angle stability and large disturbance angle stability. When a fault occurs at the terminals of a synchronous generator, the power output of the machine is greatly reduced: the rotational speed of the generator, its angular position and the transmitted power are exposed to rapid changes. However, the input power to the generator from the turbine has no time 
to change during the short period of the fault, the rotor endeavors to gain speed to store the excess energy [10].

If the fault persists long enough, the rotor angle will increase until the rotor losses all the kinetic energy it gained during the fault period is exhausted. So-called phenomenon of the transient stability, that occurs on the nearest generator to the location of disturbance. If the operating time of the circuit breakers is very important, through better communication and fast acting relays a rapid effect, the circuit breaker opens when the fault is detected and automatically recloses after a specified period. If the fault persists, the circuit breaker reopens and then recloses as before. This is repeated once more, when if the fault still persists, the breaker remains open [10]. The critical clearing time can be defined as a maximum duration that can remain a fault in the electrical system without losing their stability [5].

This paper studies the transient stability of power system based on the stability of the rotor angle and focuses on the most severe among all types fault which is the three-phase fault, in order to determine the influence of the critical clearing time of the circuit breakers for different values of fault clearing time, to ensure stability of system.

We studied the case of single machine connected to infinite bus system like [10]-[13]. We take the same system used in [13].

For the numerical solution of transient stability analysis of single machines connected to infinite bus, we used the step by step method for different values of fault clearing time. This method proposed in [11] [12] and [14]. We applied this method on our proposed system. It is a conventional and approximate method but a well tried and proven one.

We also relied on the result of [10], [12]-[15], based on the rotor angle stability that is judged from the nature of swing curve for compare and evaluate the stability of our system.

\section{ROTOR ANGLE STABILITY STUDY}

\subsection{Single machine infinite bus (SMIB)}

For analyze the rotor angle stability of power system according major disturbances, we will take the case of single machine infinite bus (SMIB). The synchronous machine can be represented by the classical model, i.e. a constant voltage source in series with a constant reactance supplying power to infinite bus through a transformer of a reactance $\mathrm{Xt}$ and line of a reactance $\mathrm{Xl}$ as shown in Figure 1. Thus the generator is represented by $\mathrm{E}$ and the infinite bus is represented by $\mathrm{U}$.

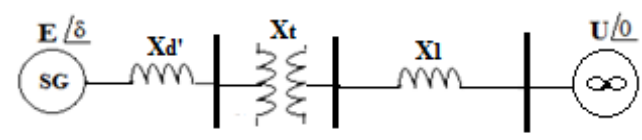

Figure 1. Single machine infinite bus

In this simple case, $X_{s}=X_{d}+X_{t}+X_{1}$

$$
E=U+j X_{S} I
$$

Where:

$$
I=\frac{E-U}{j X_{S}}
$$

The electrical power of generator is given by the following Equation (3), (4) and (5) [3]:

$$
\begin{aligned}
& P_{e}=\operatorname{Re}(\bar{E} I) \\
& =\operatorname{Re}\left(\bar{E} \frac{E-U}{j X_{s}}\right) \\
& =\operatorname{Re}\left(E \angle-\delta \frac{E \angle \delta-U \angle 0}{X_{s} \angle 90^{\circ}}\right)
\end{aligned}
$$




$$
\begin{aligned}
& =\operatorname{Re}\left(\frac{E^{2}}{X_{s}} \angle-90^{\circ}-\frac{E U}{X_{s}} \angle\left(-90^{\circ}-\delta\right)\right) \\
& =-\frac{E U}{X_{s}} \cos \left(-90^{\circ}-\delta\right) \\
& P_{e}=-\frac{E U}{X_{s}} \sin \delta
\end{aligned}
$$

$\delta$ : angle of the rotor, it is the phase difference between the internal voltage $\mathrm{E}$ of the generator and the voltage of infinite bar $U$.

This equation shows that any changes affecting the transmission power will cause a variation of rotor angle $\delta$. The curve P versus $\delta$ is known as the power angle curve and is plotted in Figure 2.

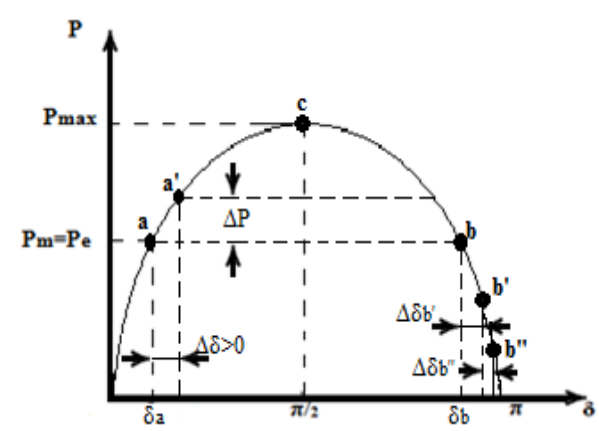

Figure 2. Power angle curve

We have for the case of generator:

$$
P_{e}=P_{m}-P_{a}
$$

Pe: Electrical power transmitted in the line.

Pm: Mechanical power obtained from the generator.

Pa: The acceleration Power. acceleration.

In normal operation, the electrical power is equal to the mechanical power, i.e. there is no

If the angle $\delta$ subject a positive change $\Delta \delta$, the power will be also subjected a change $\Delta \mathrm{P}$ and such as $\mathrm{P}_{\mathrm{m}}$ does not depend on the $\delta$, the new regime would be $\mathrm{P}_{\mathrm{e}}>\mathrm{P}_{\mathrm{m}}$. i.e. the rotor will be subjected to a braking torque. This regime continues until restoration of the initial equilibrium point " $a$ ".

In the same reasoning, if the angle $\delta$ subjects a negative variation $\Delta \delta$, the rotor will be subjected to an acceleration torque.

For the operating point " $\mathrm{b}$ ", we have for a positive deviation $\Delta \delta_{\mathrm{b}^{\prime}}: \mathrm{P}_{\mathrm{b}^{\prime}}<\mathrm{P}_{\mathrm{m}}$ and the rotor will be subjected to an acceleration torque. Under the action of this couple, the delta angle continues to increase from ( $b^{\prime}$ to $\left.b^{\prime \prime}\right)$ causing progressive decrease in power and making the machine out of synchronism.

For point "c" and for a variation $\Delta \delta>0$ the machine falls towards the instability and for a variation $\Delta \delta<0$ the machine returns to the initial state (point "c"). So we can say that on the branch $\delta\left(0^{\circ}\right.$ to $\left.90^{\circ}\right)$ of characteristic $\mathrm{P}=\mathrm{f}(\delta)$ the established regimes are stable and for the corresponding regimes $\delta\left(90^{\circ}\right.$ to $\left.180^{\circ}\right)$ are unstable.

\subsection{Study of Swing Equation}

For the case of synchronous machine connected to infinite bus, the swing equation is given by Equation (7) and (8):

$$
\frac{H}{\pi f} \frac{d^{2} \delta}{d t^{2}}=P_{m}-P_{e}=P_{a}
$$

$\mathrm{H}$ : the constant inertia. 
Where:

$P_{e}=P_{\max } \sin \delta$

Or:

$$
\begin{aligned}
& \frac{H}{\pi f} \frac{d^{2} \delta}{d t^{2}}=P_{m}-P_{\max } \sin \delta \\
& \frac{d^{2} \delta}{d t^{2}}=\frac{\pi f}{H}\left(P_{m}-P_{\max } \sin \delta\right)
\end{aligned}
$$

A plot of $\delta$ versus t called the swing curve shown in Figure 3 and two cases are possible:

If $\delta$ star to decrease after reaching a maximum value, the machine remains stable, and if $\delta$ continues to increase indefinitely, the machine loses synchronism and become unstable.

So, the system is stable if $\mathrm{d} \delta / \mathrm{dt}=0$

The system is unstable if $\mathrm{d} \delta / \mathrm{dt}>0$

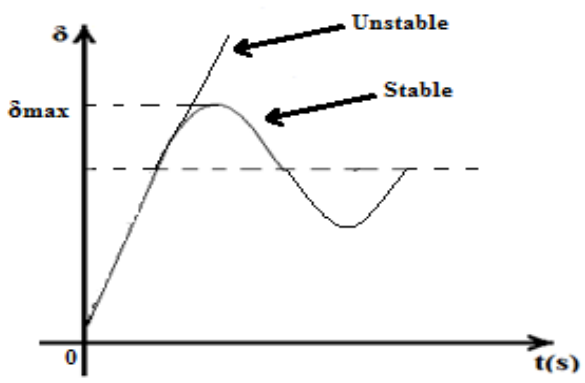

Figure 3. swing curve

\section{STEP-BY-STEP SOLUSION OF THE SWING EQUATION}

There are several methods available for the solution of the swing equation. In the case of a single machine connected to infinite bus bar, we shall treat the step-by-step method for the solution of critical clearing time associated with critical clearing angle and determine $\delta$ which may be plotted versus $t$ for a machine to obtain the swing curve of that machine. The step-by-step method is a conventional, approximate method like all numerical methods but a well tried and proven one. The angle delta is calculated as a function of time over a period long enough to determine whether delta, will increase without limit or reach a maximum and start to decrease. [11]-[12], [14], [16].

The step-by- step method is based on the following Equation (9), (10) and (11):

$$
\begin{aligned}
& \delta_{n}=\delta_{n-1}+\Delta \delta_{n} \\
& \Delta \delta_{n}=\Delta \delta_{n-1}+\frac{P_{a(n-1)}}{M}\left(\Delta t^{2}\right)
\end{aligned}
$$

The acceleration power is:

$$
P_{a(n-1)}=P_{m}-P_{e(n-1)}
$$

Where: $\delta_{(\mathrm{n}-1)}$ has been previously calculated.

It is noted that during sudden changes of situation, it is necessary to calculate the average acceleration power for the variation of the angle $\delta$. 


\section{SIMULATION AND RESULTS}

\section{4,1, Test Network}

Figure 4 shows single machine infinite bus system (SMIB) used in the simulation analysis and Table 1 present the parameter element of the system. A group of plants $9000 \mathrm{MW}$ is delivering power to infinite bar through a two transformers and feeds four transmission lines of $965 \mathrm{~km}$ at a voltage of $1200 \mathrm{kV}$ to carry the $9000 \mathrm{MW}$ that we proposed to carry. We can reduce the machine group system by system equivalent to a single machine.

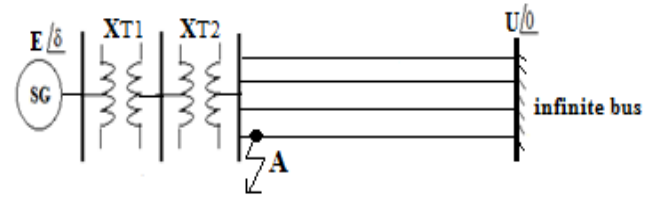

Figure 4. Power System Model

Table 1. Parameter elements of the system Electrical system parameters

\begin{tabular}{ccc}
\hline \multicolumn{3}{c}{ Electrical system parameters } \\
GS & $\mathrm{X}_{\mathrm{d}}{ }^{\prime}(\mathrm{pu})$ & 0.25 \\
& $\mathrm{H}(\mathrm{MJ} / \mathrm{MVA})$ & 3 \\
& $\mathrm{P}(\mathrm{MW})$ & 9000 \\
\hline TR1 & $\mathrm{X}_{\mathrm{T} 1}(\mathrm{pu})$ & 0.12 \\
TR2 & $\mathrm{X}_{\mathrm{T} 2}(\mathrm{pu})$ & 0.15 \\
Line & $\mathrm{X}_{\mathrm{I}}(\mathrm{pu})$ & 1.875 \\
& $\mathrm{Y} / 2(\mathrm{pu})$ & 0.382 \\
& $\mathrm{R}_{\mathrm{C}}(\Omega)$ & 250 \\
\hline \multicolumn{3}{c}{ Power Base: $9000 \mathrm{MVA}(60 \mathrm{~Hz})$} \\
& Voltage Base: $1200 \mathrm{KV}$ \\
& Impedance Base: $160 \Omega$ \\
\hline
\end{tabular}

We are now able to proceed with the study of the stability for a symmetrical three-phase fault in order to determine critical clearing time of the circuit breakers for different values of fault clearing time, to build and ensure the stability of our network.

In this paper, we relied on [10]-[15].

In [10], a model for assessment of transient stability of electrical power system was presented, where this last studied two cases for the system: single machine system and 2- machine system, in order to evaluate the transient stability from the nature of the swing curves which is a plot of the rotor angles against time and the complete system has been adopted on a program that is written in MATLAB programming language. While we studied in this work, the case of single machine connected to infinite bus system (SMIB) as approves our proposal system and the complete system has been represented in terms of Simulink blocks in a single model Figure 5.

Reference [11], [12] and [14] presented the numerical solution method step-by-step for various critical clearing time. We applied this method on our system to determine numerically the variation and the nature of the swing curve.

Reference [11] presented a stabilization of multi-machine system connected to infinite bus, where this last used two machine interconnected system for 3-phase fault and two different values of fault clearing time at $0.08 \mathrm{~s}$ and $0.275 \mathrm{~s}$. We also used two different values of fault clearing time at $0.08 \mathrm{~s}$ and $0.1 \mathrm{~s}$, to determine the nature of rotor angle $\delta$ curve according to time and also we were able to obtain the following curves: the electric power, the acceleration power and the angular speed of the generator.

In [13] as is evident, we studied the transient stability of electrical system based on the stability of the rotor angle to determine the number of line for one value of critical clearing time $0.1 \mathrm{~s}$ and two hypothesis: four lines and fives lines. While in this paper, to further improve system efficiency we took the first hypothesis in [13] for four lines and we tried to evaluate the operation system for 3-phase fault through the determination a value of fault clearing time between two values.

The fault is assumed to the input line (Fig.4: point A). We can consider in the case of three-phase symmetrical fault steady state and also the voltage at the terminals of the alternator is kept constant because of its excitation system. This fact allows us to consider the unit voltage $U$ for calculations $\left(X^{\prime} d=0\right)$.

We applied the method step by step on our system (SMIB), to determine numerically the stability of rotor angle $\delta$. The calculations for this method have been performed by a program using MATLAB. Table 1

The Transient Stability Study of a Synchronous Generator Based on the Rotor Angle Stability (Fetissi Selwa) 
and Table 2 present the step-by-step method for fault cleared time respectively at $0.08 \mathrm{~s}$ and $0.1 \mathrm{~s}$. With $\Delta \mathrm{t}=$ $0.05 \mathrm{~s}$.

Table 2. Step-by-Step method for fault cleared at $0.08 \mathrm{~s}$

\begin{tabular}{cccccc}
\hline $\mathrm{t}(\mathrm{sec})$ & $\mathrm{Pe}(\mathrm{pu})$ & $\mathrm{Pa}(\mathrm{pu})$ & $\begin{array}{c}{\left[\left(\Delta \mathrm{t}^{2}\right) / \mathrm{M}\right] \mathrm{Pa}} \\
(\mathrm{deg})\end{array}$ & $\begin{array}{c}\Delta \delta_{\mathrm{n}} \\
(\mathrm{deg})\end{array}$ & $\begin{array}{c}\delta_{\mathrm{n}} \\
(\mathrm{deg})\end{array}$ \\
\hline $0^{-}$ & 1 & 0.00 & 0.00 & 0.00 & 47.67 \\
$0^{+}$ & 0 & 1.00 & 9.00 & 0.00 & 47.67 \\
$0_{\text {avg }}$ & 0 & 0.50 & 4.5 & 4.5 & 47.67 \\
0.05 & 0 & 1.00 & 9.00 & 13.5042 & 52.1742 \\
0.1 & 1.2315 & -0.2315 & -2.0832 & 11.4211 & 65.6785 \\
0.15 & 1.3173 & -0.3173 & -2.8556 & 8.5655 & 77.0995 \\
0.20 & 1.3475 & -0.3475 & -3.1278 & 5.4377 & 85.6650 \\
0.25 & 1.3511 & -0.3511 & -3.1603 & 2.2773 & 91.1027 \\
0.30 & 1.3490 & -0.3490 & -3.1414 & -0.8641 & 93.3800 \\
0.35 & 1.3501 & -0.3501 & -3.1503 & -4.0150 & 92.5158 \\
0.40 & 1.3509 & -0.3509 & -3.1584 & -7.1734 & 88.5008 \\
0.45 & 1.3359 & -0.3359 & -3.0235 & -10.1970 & 81.3274 \\
0.50 & 1.2788 & -0.2788 & -2.5089 & -12.7059 & 71.1304 \\
0.55 & $\ldots$. & $\ldots$. & $\ldots$. & $\ldots$. & 58.4245 \\
\hline
\end{tabular}

Table 3. Step-by-Step method for fault cleared at $0.1 \mathrm{~s}$

\begin{tabular}{cccccc}
\hline $\mathrm{t}(\mathrm{sec})$ & $\mathrm{Pe}(\mathrm{pu})$ & $\mathrm{Pa}(\mathrm{pu})$ & $\begin{array}{c}{\left[\left(\Delta \mathrm{t}^{2}\right) / \mathrm{M}\right] \mathrm{Pa}} \\
(\mathrm{deg})\end{array}$ & $\begin{array}{c}\Delta \delta_{\mathrm{n}} \\
(\mathrm{deg})\end{array}$ & $\begin{array}{c}\delta_{\mathrm{n}} \\
(\mathrm{deg})\end{array}$ \\
\hline $0^{-}$ & 1.00 & 0.00 & 0.00 & 0.00 & 47.67 \\
$0^{+}$ & 0.00 & 1.00 & 9.00 & 0.00 & 47.67 \\
$0_{\text {avg }}$ & 0.00 & 0.50 & 4.5042 & 4.5042 & 47.67 \\
0.05 & 0.00 & 1.00 & 9.00 & 13.5042 & 52.1742 \\
$0.1^{-}$ & 0.00 & 1.00 & 0.00 & 0.00 & 65.6785 \\
$0.1^{+}$ & 1.2315 & -0.2315 & 0.00 & 0.00 & 65.6785 \\
0.1 & 0.00 & 0.3843 & 3.4584 & 16.9626 & 65.6785 \\
0.15 & 1.3403 & -0.3403 & -3.0624 & 13.9002 & 82.6411 \\
0.20 & 1.3426 & -0.3426 & -3.0834 & 10.8168 & 96.5413 \\
0.25 & 1.2899 & -0.2899 & -2.6087 & 8.2081 & 107.3581 \\
0.30 & 1.2191 & -0.2191 & -1.9717 & 6.2364 & 115.5662 \\
0.35 & 1.1485 & -0.1485 & -1.3366 & 4.8998 & 121.8026 \\
0.40 & 1.0835 & -0.0835 & -0.7514 & 4.1484 & 126.7024 \\
0.45 & 1.0222 & -0.0222 & -0.2000 & 3.9484 & 130.8508 \\
0.50 & 1.0411 & 0.0411 & 0.3697 & 4.3181 & 134.7993 \\
0.55 & $\ldots$. & $\ldots$. & $\ldots$. & $\ldots$. & 139.1174 \\
\hline
\end{tabular}

According to the two tables, we find that the rotor angle $\delta$ reach a maximum of and start to decrease for fault cleared at $0.8 \mathrm{~s}$, While it increase without limit for fault cleared at $0.1 \mathrm{~s}$. We can say that the generator remains its stability at $0.8 \mathrm{~s}$ but it loses its stability at $0.1 \mathrm{~s}$.

The complete system has been represented in terms of Simulink blocks in a single model Fig.5. The simulation is done for a period of $2 \mathrm{~s}$. We observed through to changing the fault clearing times extent stability of the system from figures below.

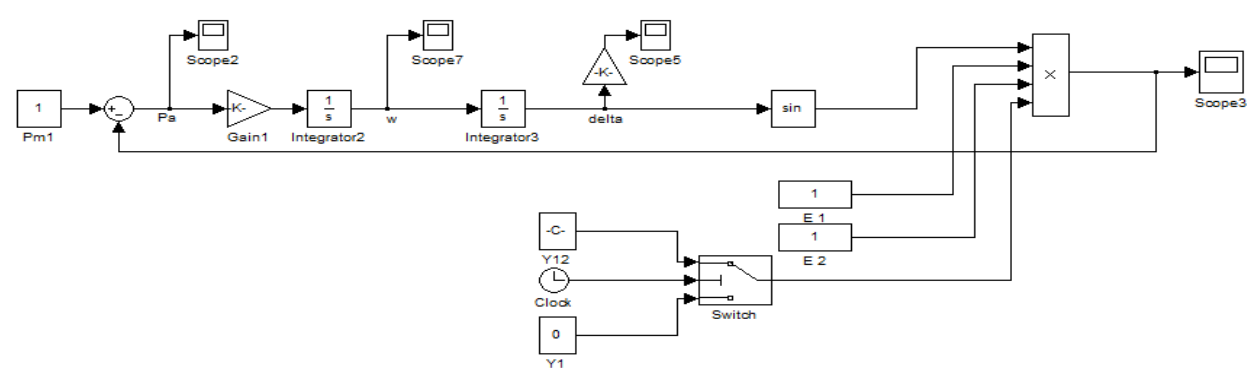

Figure 5. Simulation block diagram of the system in MATLAB / SIMULINK

Before the fault, the electrical power is equal to the mechanical power. The generator is in equilibrium state and its speed remains constant. As the electrical power is unitary, it is possible to determine the initial angle value of $\delta_{0}$ by $\mathrm{Pe}=\mathrm{EU} / \mathrm{X}_{\mathrm{s}} \sin \delta$. 
At the default phase, the power transferred from the generator $(\mathrm{Pe})$ will go to zero. As though $\mathrm{Pa}=\mathrm{Pm}-\mathrm{Pe}$ and $\mathrm{Pm}$ is considered constant and unitary, $\mathrm{Pa}$ also becomes unitary.

After removal the fault, we get into the same situation as before the fault $\mathrm{Pe}=\mathrm{EU} / \mathrm{X}_{\mathrm{s}} \sin \delta$, but $\delta$ has not the same value of $\delta_{0}$. Therefore the electrical power and generator speed are becoming variable. The generator going to continue to swing until he finds an equilibrium point, otherwise it loses its synchronism and this will be according to the influence of the critical clearing time of the circuit breaker on the network.

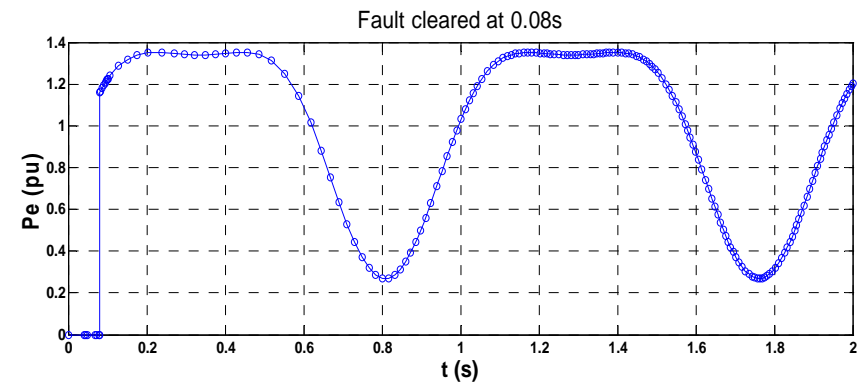

(a) Electrical power of the generator

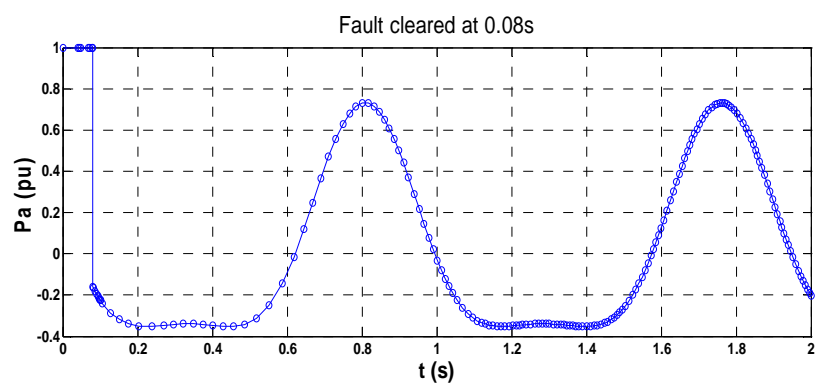

(b) Acceleration power of the generator

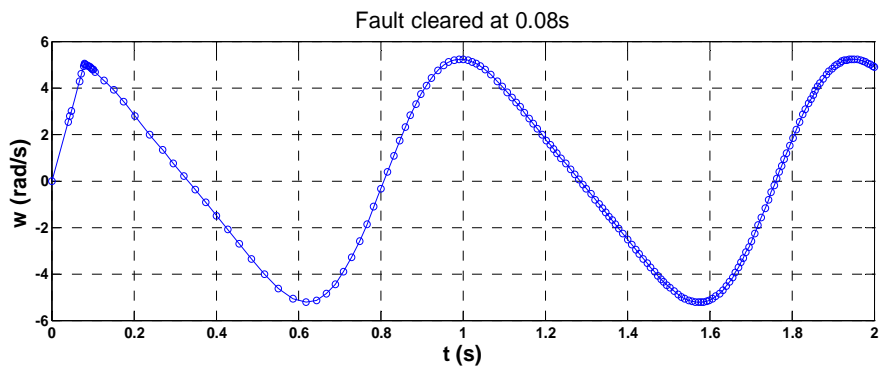

(c) The angular speed of the generator

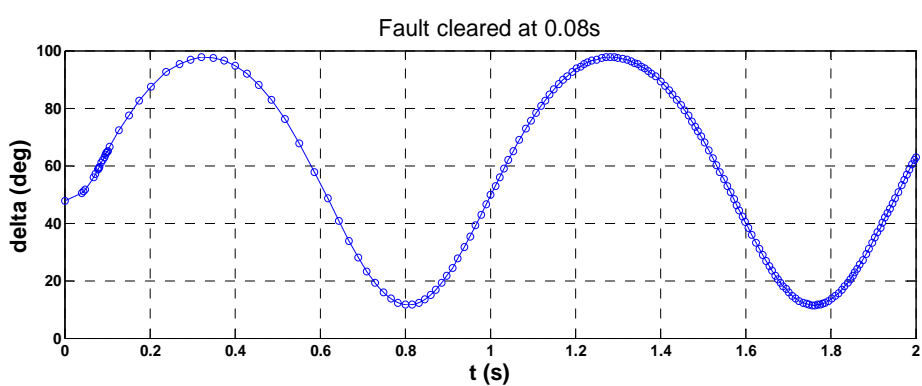

(d). The rotor angle $\delta$ of the generator

Figure 6. Simulation results of the system for fault cleared time $=0.08 \mathrm{~s}$ 


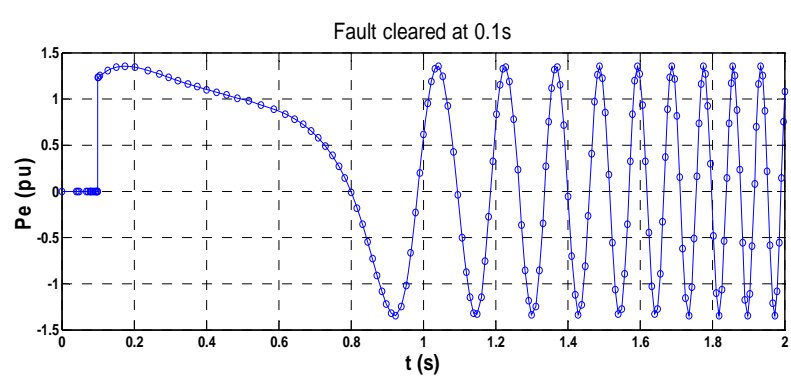

(a) Electrical power of the generator

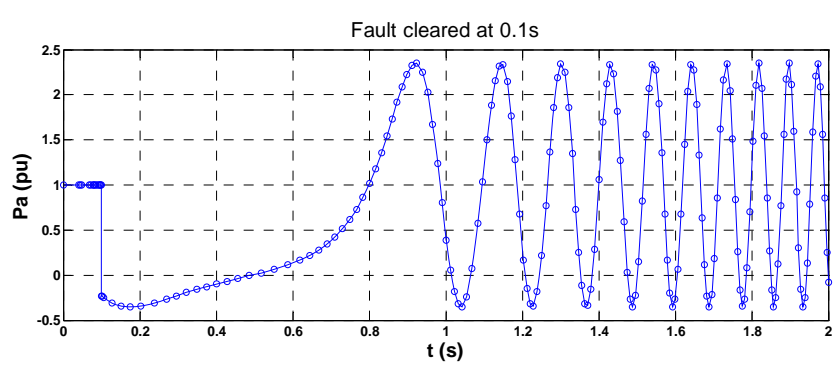

(b) Acceleration power of the generator

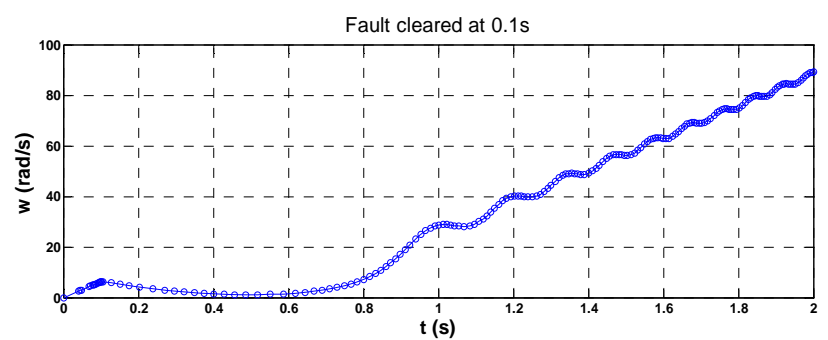

(c) The angular speed of the generator

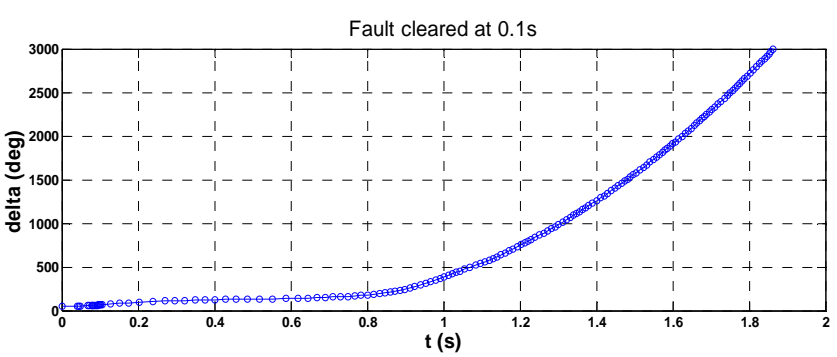

(d) The rotor angle $\delta$ of the generator

Figure 7. Simulation results of the system for fault cleared time $=0.1 \mathrm{~s}$

Figure 6(a) and (b) show the electric power and the acceleration power of the generator for the system with fault clearing time $=0.08 \mathrm{~s}$, while Figure $6(\mathrm{c})$ and (d) show the angular speed and the internal angle $\delta$ of the generator. The results of the work indicate that from 0 to $0.08 \mathrm{~s}$ the electrical power equal to zero, while the acceleration power go to 1 p.u. This shows that at this time the acceleration power equal to mechanic power. We also observe that delta take their initial value of $47.67^{\circ}$ at $0 \mathrm{~s}$ and increase to $59.14^{\circ}$ at $0.08 \mathrm{~s}$, also the angular speed increase from $0 \mathrm{rad} / \mathrm{s}$ at $0 \mathrm{~s}$ to $5.02 \mathrm{rad} / \mathrm{s}$ at $0.08 \mathrm{~s}$. In $0.08 \mathrm{~s}$ the fault is cleared, we observe that the electrical power increase to 1.16 p.u while the acceleration power decrease to -0.16 p.u. The angular speed begins to decrease and the rotor angle $\delta$ continues to increase until it reaches a maximum value of $97.55^{\circ}$ and then begins to decrease. The electrical power and the acceleration power continue to vary with the variation of delta.

The results show that the power system is stable. The electric power and the acceleration power are depreciated, the angular speed and the rotor angle $\delta$ varies according to a damped oscillatory pace with time around an equilibrium point. We can say that the kinetic energy gained during fault is absorbed by the system and the generator maintains its stability after fault clearance and is synchronized with the network. 
Figure 8(a), (b), (c) and (d) show the system response for fault clearing time $=0.1 \mathrm{~s}$. In this time the electrical power increase to $1.23 \mathrm{p} . \mathrm{u}$ and the acceleration power decrease to $-1.23 \mathrm{p} . \mathrm{u}$, then they continue to oscillate rapidly and indefinite way. We note also the angular speed and the rotor angle increases continuously with time without pass through a maximum value. The simulation results indicate that the system become unstable and the generator between in over speed after elimination of the fault and losing synchronism with the network.

We compared the results obtained with that obtained in [10], [12], [14]-[15] and we came to the same results by studying the transit stability that the transient stability is judged from the nature of the swing curves it is also observed by determining swing curves for various clearing times that we have been able to find the time permitted before clearing a fault to regain the stability of our network.

And by comparing the results obtained with also in [13], it can be noted that the system operates in the most efficient and less costly through a change in the fault clearing time of circuit breaker compared with a change in the number of lines.

\section{CONCLUSION}

This paper is based on the stability of the rotor angle study; more précising from a simulation of power system for different values of fault clearing times. In the case of a default, the electrical power drops to zero as we explained previously. In this time, the circuit breaker opened the circuit was then closed again to clear the fault. The stability analysis of our system is performed for the case of most severe 3-phase fault, using a system of machine connected to infinite bus, so if the fault is cleared within a time of $0.08 \mathrm{~s}$, the generator is stable with the network. However if fault cleared in $0.1 \mathrm{~s}$ the generator will be unstable.

From a two values of fault clearing times that we have chosen, we can conclude that the stability of power system depends on its duration of the critical clearing time of the circuit breaker, to avoid the risk of over speed in case of short circuiting. Finally, we can say that the resulting simulations are consistent with those found in the literature.

\section{REFERENCES}

[1] Syed A. Nasar, "Electric Power System,” McGraw-Hill, 1st edition, 1989.

[2] Prabha Kundur, et al., "Joint Task Force on Stability Terms and Definitions. Definition and Classification of Power System Stability," IEEE Transactions on Power Systems, Vol. 19, No. 2, pp. 1387-1401, 2004.

[3] Jignesh S. Patel and Manish N. Sinha, "Power System Transient Stability Analysis Using ETAP Software," National Conference on Recent Trends in Engineering \& Technology, 2011.

[4] Komal S. Shetye, Thomas J. Overbye, and James F. Gronquist. "Validation of Power System Transient Stability Results," Power and Energy Conference at Illinois (PECI), 2012 IEEE, pp. 1-8.

[5] Bablesh Kumar Jha, Ramjee Prasad Gupta, Upendra Prasad, "Combined Operation of SVC, PSS and Increasing Inertia of Machine for Power System Transient Stability Enhancement," International Journal of Applied Power Engineering (IJAPE), Vol. 3, No. 1, pp. 15-22, 2014.

[6] G. R. Mohapatra and A. Kalam, "Dynamic Stability Analysis of Renewable Energy Sources Interconnected to the Distribution Networks," Australasian Universities Power Engineering Conference (AUPEC'08), pp. 1-4, 2008.

[7] Sara Eftekharnejad, et al., "Impact of Increased Penetration of Photovoltaic Generation on Power Systems," IEEE Transactions on Power Systems, Vol. 28, No. 2, pp. 893-901, 2013.

[8] H. Alkhatib, Etude De La Stabilité Aux Petites Perturbations dans les Grandes Réseaux Electriques : Optimisation de la Régulation par une Méthode Métaheuristique, Thèse de Doctorat, Université PAUL CEZANNE D'AIXMARSEILLE (AIX- MARSEILLE III), 2008.

[9] C. APPRAEZ, Etude Comparative de Méthodes de Simulation de La Stabilité Transitoire, école de technologie supérieure, Université du Québec, 2012.

[10] Ganiyu A. Ajenikoko and Anthony A. Olaomi, "A Model for Assessment of Transient Stability of Electrical Power System," International Journal of Electrical and Computer Engineering (IJECE), Vol. 4, No. 4, pp. 498-511, 2014.

[11] D. P. Kothari, I. J. Nagrath, "Modern Power System Analysis," Tata Mc Graw-Hill Education, Third Edition, 2003.

[12] Samita Padhi and Bishnu Prasad Mishra, "Numerical Method Based Single Machine Analysis for Transient Stability," International Journal of Emerging Technology and Advanced Engineering. Vol. 4, No. 2, pp. 330-335, 2014.

[13] Fetissi Selwa and Labed Djamel, "Transient Stability Analysis of Synchronous Generator in Electrical Network," International Journal of Scientific \& Engineering Research, Vol. 5, No. 8, pp. 55-59, 2014.

[14] Chandra Shekhar Sharma, "Transient Stability Analysis of Single Machine Infinite Bus System by Numerical Methods," International Journal of Electrical and Electronics Research, Vol. 2, No. 3, pp. 158-166, 2014.

[15] Kanika Gupta and Ankit Pandey, "Stabilization Of Multi Machine System Connected To Infinite Bus," International Journal of Scientific \& Technology Research, Vol. 2, No. 8, pp. 82-85, 2013.

[16] John J. Grainger and William D. Stevenson Jr, "Power System Analysis," McGraw-Hill Science/Engineering. 1st Edition, 1994. 